\title{
PENGARUH PEMBERIAN REBUSAN DAUN SALAM (SYZYGIUM POLYANTHUM) TERHADAP PENURUNAN TEKANAN DARAH TINGGI DI DESA PLOSOWAHYU KECAMATAN LAMONGAN KABUPATEN LAMONGAN
}

\author{
Arifal Aris \\ Program Studi S1 Keperawatan STIKES Muhammadiyah Lamongan \\ Email : virgianti_nf@yahoo.com
}

\begin{abstract}
Hypertension is an increase in blood pressure above the normal limit with a systolic value of $140 \mathrm{mmHg}$ and a diastolic $90 \mathrm{mmHg}$. Giving boiled salam leaves is an alternative to controlling blood pressure in patients with hypertension. The purpose of this study was to determine the effect of salam leaves decoction on reducing blood pressure in hypertensive patients in Plosowahyu, Lamongan. The design of this study used pre experimental with a population 35 respondents then sampling using simple random sampling and getting a sample of 32 respondents using the onegroup approach to pre-post test design. The independent variable in this study was the respiration of salam leaves and the dependent variable was measurement of high blood pressure. The data of this study were taken from the results of observation of high blood pressure before and after being given boiled salam leaves in February 2018. Data were tabulated and analyzed using the Wilcoxon test with a level of $\alpha=0.05$. The results of analysis using the Wilcoxon test obtained a value of $Z=-5.507$ with $p=0,000$. The results showed that all of them had a drop in blood pressure of 32 respondents (100\%), so Ho was rejected, it means that there was an effect of giving boiled salam leaf to decrease in high blood pressure in Plosowahyu Lamongan. Looking the results of the study, it is expected that hypertension sufferers in the Plosowahyu, Lamongan. Consume boiled salam leaves as a complementary therapy can reduce high blood pressure.
\end{abstract}

Keywords: Salam leaves, high blood pressure (hypertension)

\section{PENDAHULUAN}

Hipertensi merupakan suatu kondisi medis berupa peningkatan tekanan darah diatas batas normal.Untuk memastikan hipertensi dengan melakukan pengukuran tekanan darah.Ukuran batas normal adalah 120-140 mmHg sitolik dan 80-90 $\mathrm{mmHg}$ diastolik. Jadi, seseorang disebut mengindap hipertensi bila tekanan darahnya diatas 140/90 mmHg (Manan, 2011). Hipertensi ditemukan dalam dua tipe yaitu hipertensi primer dan hipertensi sekunder.Hipertensi primer biasanya dimulai secara berangsur tanpa keluhan dan gejala sebagai penyakit benigna yang secara berlahan berlanjut menjadi keadaan maligna. Sedangkan hipertensi sekunder disebabkan oleh penyakit renal atau penyebab lain yang dapat diidentifikasi (Kowalak, 2011). 
Hipertensi merupakan penyebab nomor satu kematian didunia. Data Join National Comitte on Prevention, Detection, Evaluation, and Treatment on High Blood Presure VII mengatakan hampir 1 miliyar penduduk didunia mengindap hipertensi (Prasetyaningrum, 2014). Menurut catatan Badan Kesehatan Dunia(WHO), diseluruh dunia sekitar 972 juta orang atau 26,4\% mengindap hipertensi, angka ini kemungkinan meningkat menjadi 29,2\% ditahun 2025 nanti. Dari data 972 juta pengindap hipertensi 333 juta berada dinegara berkembang, termasuk Indonesia. Hipertensi primer adalah tipe paling umum dan termasuk 35\%95\% dari populasi hipertensi, sedangkan hipertensi sekunder terhitung 5\%-15\% dari populasi hipertensi. Hipertensi merupakan penyebab kematian yang mencapai 6,7\% dari populasi hipertensi, pada semua umur di Indonesia (Destiara, 2017).

Berdasarkan data kunjungan dari status kesehatan yang ada di Puskesmas Lamongan khususnya di wilayah Desa Plosowahyu Kecamatan Lamongan Kabupaten Lamongan bahwa penderita hipertensi pada bulan Januari sampai dengan Juni tahun 2017 sebanyak 35 pasien. Sedangkan hasil survey awal yang dilakukan pada penduduk di Desa Plosowahyu Kecamatan LamonganKabupaten Lamongan pada tanggal 05 Oktober 2017 didapatkan data dari 10 orang yang dilakukan pemeriksaan tekanan darah terdapat $5(50 \%)$ orang mengalami hipertensi ringan, $2(20 \%)$ orang mengalami hipertensi sedang, 1 (10\%) orang mengalami hipertensi berat dan 2 (20\%) orang lainnya tekanan darahnya normal. Rata-rata tekanan darah mereka yang menderita hipertensi berkisar antara: tekanan sistolik 150-190 mmHg dan tekanan diastolik 90-110 mmHg.

Beberapa faktor resiko hipertensi yang tidak dapat dihindari atau dirubah seperti Ras,umur, jenis kelamin dan riwayat keluarga. Sedangkan faktor yang dapat dihindari karena dapat memperberat keadaan hipertensi antara lain obesitas, kurang aktivitas fisik, merokok, sensitivitas natrium, kadar kalium rendah, minuman alkohol berlebih, dan stress (Dalimartha, 2008).

Tekanan darah yang terus meningkat menyebabkan jantung bekerja ekstra keras, jika diderita dalam jangka waktu lama dapat menimbulkan bebagai macam komplikasi. Tekanan darah tinggi dapat merusak bagian dalam dari arteri yang kecil, kemungkinan dapat menyebabkan pembekuan darah. Hal ini terjadi maka dapat menyebabkan serangan jantung, kebutaan, gagal ginjal dan stroke (Nurul, 2011).

Hipertensi dapat dikontrol hingga mencapai nilai normal dan stabil.Hipertensi dapat diminimalkan dengan tindakan terapi farmakologis dan terapi nonfarmakologis yang dapat membantu proses pencegahan atau penundaan terjadinya masalah kesehatan akibat hipertensi. Penanganan secara farmakologis terdiri banyak sekali tipe obat yang dapat digunakan untuk pengobatan tekanan darah tinggi seperti obat golongan ACE inhibitor, deuretiksimpatetik, vasodilator, $\beta$ bloker, $\alpha$-bloker dengan memperhatikan tempat, mekanisme kerja dan tingkat kepatuhan.Pengobatan hipertensi yang banyak dikonsumsi masyarakat biasanya obat kimia yang selalu dikonsumsi sehingga menimbulkan ketergantungan. 
Meskipun kemajuan dalam penemuan obat-obatan anti hipertensi, perlu dicari obat-obatan tradisional sehingga pasien tidak tergantung selamanya pada obat medis yang dapat menyebabkan efek samping.Obat tradisional memiliki harga yang relatif murah dan efek samping yang lebih sedikit. Salah satu obat tradisonal yang dapat menurunkan tekanan darah adalah daun salam, merupakan salah satu dari jenis terapi herbal untuk menangani penyakit hipertensi (Nisa, 2012). Kandungan kimia dalam daun salam yang diduga berperan terhadap penurunan tekanan darah adalah flavonoid, minyak atsiri, Kalium dan alkaloid yang bersifat deuretik.Senyawa flavonoid pada daun salam dapat melancarkan peredaran darah keseluruh tubuh dan mencegah terjadinya penyumbatan pada pembuluh darah (atherosklerosis), selain itu senyawa flavonoid juga dapat menurunkan Systemic Vascular Resisten (SVR), menyebabkan vasodilatasi dan mempengaruhi kerja ACE inhibitor yang mampu menghambat terjadinya perubahan angiotensin I menjadi angiotensin II. Efek vasodilatasi dan ACE inhibitor dapat menurunkan tekanan darah (Junaedi, 2013). Minyak atsiri yang terkandung pada daun salam menghasilkan aroma khas yang memberikan efek relaks dan dapat menurunkan tingkat stres yang menjadi faktor pendorong timbulnya hipertensi (Winarto, 2008). Sedangkan zat kimia alami seperti kalium dan alkaloid yang bersifat deuretik yaitu membantu ginjal mengeluarkan kelebihan cairan dan garam dari dalam tubuh (Vania, 2012).

\section{METODE PENELITIAN}

Desain penelitian ini menggunakan metode Pre-Eksperimentaldengan pendekatan one group pre post test design.Sampel diambil dari orang yang menderita hipertensi yang berada di Desa Plosowahyu Kecamatan Lamongan Kabupaten Lamongan sebanyak 32 responden. Variabel independen dalam penelitian ini adalah pemberian rebusan daun salam, sedangkan variabel dependennya adalah pengukuran tekanan darah. Pengumpulan data dalam penelitian ini menggunakan lembar kuasioner untuk data karakteristik responden serta lembar observasi untuk data khusus tekanan darah sebelum perlakuan dan sesudah perlakuan, analisis penelitian menggunakan uji statistikWilcoxon Match PairsTest

\section{HASIL DAN PEMBAHASAN}

Tabel 1. Karakteristik Jenis Kelamin Penderita Hipertensi di Desa Plosowahyu Kecamatan Lamongan Bulan Februari Tahun 2018

\begin{tabular}{ccc}
\hline Jenis & Frekuensi & $\begin{array}{c}\text { Prosentase } \\
(\%)\end{array}$ \\
Kelamin & & 18,8 \\
Laki-laki & 6 & 81,3 \\
Perempuan & 26 & 100 \\
\hline Jumlah & 32 & \\
\hline
\end{tabular}


Berdasarkan tabel 1menunjukkan bahwa dari 32 penderita Februari hampir seluruhnya berjenis kelamin perempuan yaitu sebanyak 26 orang $(81,3 \%)$.

Tabel 2. Karakteristik Umur Penderita Hipertensi di Desa Plosowahyu Kecamatan Lamongan Bulan Februari Tahun 2018

\begin{tabular}{ccc}
\hline $\begin{array}{c}\text { Umur } \\
\text { (tahun) }\end{array}$ & Frekuensi & $\begin{array}{c}\text { Prosentase } \\
(\%)\end{array}$ \\
\hline $41-50$ & 5 & 15,6 \\
$51-60$ & 12 & 37,5 \\
$61-70$ & 8 & 25,0 \\
$>70$ & 7 & 21,9 \\
\hline Jumlah & 32 & 100 \\
\hline
\end{tabular}

Berdasarkan tabel 2 menunjukkan bahwa dari 32 penderita hampir sebagian berumur 51-60 tahun sebanyak 12 orang (37,5\%), sedangkan sebagian kecil berumur 41-50 tahun sebanyak 5 orang $(15,6 \%)$.

Tabel 3 Distribusi Penderita Hipertensi Berdasarkan Tekanan Darah Sebelum Diberikan Rebusan Daun Salam (Syzygium Polyanthum)

\begin{tabular}{lcc}
\hline \multicolumn{1}{c}{ Tekanan Darah } & Frekuensi & $\begin{array}{c}\text { Prosentase } \\
(\%)\end{array}$ \\
\hline Normal & 0 & 0 \\
Hipertensi Ringan & 16 & 50,0 \\
Hipertensi sedang & 9 & 28,1 \\
Hipertensi Berat & 7 & 21,9 \\
\hline \multicolumn{1}{c}{ Jumlah } & 32 & 100 \\
\hline
\end{tabular}

Berdasarkan tabel 3 menunjukkan bahwa sebelum diberikan rebusan daun salam sebagian penderita mengalami hipertensi ringan sebanyak 16 orang (50\%), hampir sebagian penderita mengalami hipertensi sedang sebanyak 9 orang $(28,1 \%)$, sedangkan sebagian kecil penderita yang mengalami hipertensi berat sebanyak 7 orang $(21,9 \%)$ dan tidak satupun penderita hipertensi yang mengalami tekanan darah normal $(0 \%)$.

Tabel 4 Distribusi Penderita Hipertensi Sesudah Pemberian Rebusan Daun Salam (Syzygium Polyanthum)

\begin{tabular}{lcc}
\hline \multicolumn{1}{c}{ Tekanan Darah } & Frekuensi & $\begin{array}{c}\text { Prosentase } \\
(\%)\end{array}$ \\
\hline Normal & 17 & 53,1 \\
Hipertensi Ringan & 9 & 28,1 \\
Hipertensi sedang & 6 & 18,8 \\
Hipertensi Berat & 0 & 0 \\
\hline \multicolumn{1}{c}{ Jumlah } & 32 & 100 \\
\hline
\end{tabular}


Berdasarkan tabel 4 menunjukkan bahwa sesudah diberikan rebusan daun salam sebagian besar penderita hipertensi mengalami tekanan darah normal sebanyak 17 orang $(53,1 \%)$, sedangkan sebagian kecil penderita mengalami hipertensi sedang sebanyak 6 orang $(18,8)$ dan tidak satupun penderita tekanan darah mengalami hipertensi berat $(0 \%)$.

Tabel 5 Pengaruh Pemberian Rebusan Daun Salam (Syzygium Polyanthum) Terhadap Penurunan Tekanan Darah Pada Penderita Hipertensi

\begin{tabular}{lccccc}
\hline \multicolumn{1}{c}{ Sebelum } & Normal & $\begin{array}{c}\text { Setelah } \\
\text { HT } \\
\text { Ringan }\end{array}$ & $\begin{array}{c}\text { HT } \\
\text { Sedang }\end{array}$ & $\begin{array}{c}\text { HT } \\
\text { Berat }\end{array}$ & Jml \\
\hline HT & 16 & 0 & 0 & 0 & 16 \\
Ringan & $(50,0 \%)$ & $(0 \%)$ & $(0 \%)$ & $(0 \%)$ & $(50,0 \%)$ \\
HT & 1 & 8 & 0 & 0 & 9 \\
Sedang & $(3,1 \%)$ & $(25.0 \%)$ & $(0 \%)$ & $(0 \%)$ & $(51,6 \%)$ \\
HT & 0 & 1 & 6 & 0 & $7(21,9 \%)$ \\
Berat & $(0 \%)$ & $(3,1 \%)$ & $(18,8 \%)$ & $(0 \%)$ & \\
& & & & & \\
\multicolumn{1}{c}{ Jumlah } & 17 & 9 & 6 & 0 & 32 \\
& $(53,1 \%)$ & $(28,1 \%)$ & $(18,8 \%)$ & $(0 \%)$ & $(100 \%)$ \\
\hline
\end{tabular}

Berdasarkan tabel 5 menunjukkan bahwa 32 responden, sebelum terapi rebusan daun salam yang mengalami hipertensi berat sebanyak 7 responden $(21,9 \%)$ dan setelah diberikan terapi rebusan daun salam sebagian menjadi hipertensi sedang sebanyak 6 responden (18,8\%), sedangkan sebagian kecil berubah menjadi hipertensi ringan sebanyak 1 responden $(3,1 \%)$, kemudian dari jumlah responden yang mengalami hipertensi sedang sebelum terapi rebusan daun salam sebanyak 9 responden $(28,1 \%)$ dan setelah diberikan terapi rebusan daun salam sebagian menjadi hipertensi ringan sebanyak 8 responden $(25,0 \%)$, sebagian kecil menjadi normal sebanyak 1 responden $(3,1 \%)$. Sedangkan dari 16 responden $(50,0 \%)$ dengan hipertensi ringan sebelum pemberian terapi rebusan daun salam dan setelah diberikan terapi rebusan daun salam seluruhnya responden menjadi kategori normal sebanyak 16 responden $(50,0 \%)$.

Dari hasil uji statistik Wilcoxon Sign Rank Test didapatkan hasil nilai Z = 5,507 dan $\mathrm{p}=0,000$ dimana $(\mathrm{p}<0,05) . \mathrm{H}_{0}$ ditolak dan $\mathrm{H}_{1}$ diterima, artinya ada pengaruh pemberian rebusan daun salam terhadap penurunan tekanan darah pada penderita hipertensi di Desa Plosowahyu Kecamatan Lamongan tahun 2018.

Berdasarkan tabel 3 menunjukkan pengukuran tekanan darah sebelum diberikan rebusan daun salam didapatkan sebagian penderita hipertensi mempunyai hipertensi ringan sebanyak 16 orang (50\%), kemungkinan disebabkan oleh faktor keturunan dan gaya hidup. Selain dari dua faktor tersebut faktor lain yang dapat mempengaruhi hipertensi adalah usia, jenis kelamin, pekerjaan dan kemungkinan 
juga pada tingkat pendidikan responden, dikarenakan pendidikan yang minim dapat mempengaruhi gaya hidup dan pola aktivitas sehari-hari pada setiap individu. Pada saat penelitian hampir seluruhnya penderita hipertensi adalah perempuan. Pada tabel 1 menunjukkan bahwa penderita hipertensi berjenis kelamin perempuan sebanyak 26 orang $(81,3 \%)$. dapat disimpulkan bahwa hipertensi lebih terserang pada perempuan dibandingkan dengan laki-laki.

Pada mulanya hipertensi lebih mudah menyerang kaum laki-laki dari pada perempuan, hal itu kemungkinan karena laki-laki banyak memiliki faktor pendorong terjadinya hipertensi, seperti stres, kelelahan dan makan tidak terkontrol. Tetapi hal ini akan terjadi sebaliknya setelah memasuki masa menopause hipertensi pada perempuan akan meningkat akibat dari faktor hormonal (Dalimartha, 2008). Jenis kelamin sangat mempengaruhi terjadinya hipertensi karena dipengaruhi oleh ketidakseimbangan hormonal, dimana pada masa menopause pada perempuan selsel akan kehilangan hormon esterogen sehingga berpengaruh pada keelastisan pembuluh darah dan kerja pada sistem kardiovaskuler, sehingga wanita lebih cenderung memiliki tekanan darah tinggi (Prasetyaningrum. 2014)

Selain jenis kelamin, penyakit hipertensi lebih rentan terjadi pada usia tua. Penambahan usia dapat meningkatkan resiko terjangkitnya penyakit hipertensi, walaupun penyakit hipertensi bisa terjadi pada segala usia tetapi paling sering terjadi pada orang dewasa berusia 35 tahun atau lebih. Pada tabel 2 menunjukkan sebagian besar penderita hipertensi berusia 51-60 tahun sebanyak $(53,1 \%)$, sedangkan sebagian kecil berusia 41-50 tahun sebanyak $(15,6 \%)$.

Meningkatnya tekanan darah seiring dengan bertambahnya usia memang sangat wajar hal ini disebabkan adanya perubahan alami pada jantung, pembuluh darah, dan kadar hormon. Pada usia tua lebih rentan terkena hipertensi karena pada usia tua arteri lebih keras dan kurang fleksibel terhadap darah, sehingga dapat mengakibatkan peningkatan tekanan darah sistolik (Dalimartha, 2008).

Hal ini di sebabkan oleh karena banyaknya penurunan fungsi system tubuh secara fisiologis dalam bertambahnya usia, karena pada usia tua pembuluh darah sudah mulai kehilangan keelastisan, sehingga dapat mempengaruhi kerja sistem kardiovaskuler dan dapat mengakibatkan hipertensi, sehingga pada usia tua lebih rentan terkena hipertensi

Berdasarkan tabel 4 setelah diberikan rebusan daun salam menunjukkan sebagian besar penderita hipertensi mengalami tekanan darah normal sebanyak 17 orang $(53,1 \%)$, sedangkan sebagian kecil penderita mengalami hipertensi sedang sebanyak 6 orang $(18,8 \%)$ dan tidak satupun penderita tekanan darah mengalami hipertensi berat $(0 \%)$. Hal ini menunjukkan terdapat penurunan tekanan darah sesudah diberikan rebusan daun salam. Penurunan tekanan darah ini terjadi karena responden telah berpatisipasi dengan baik pada saat penelitian.Dalam penelitian ini membuktikan bahwa rebusan daun salamdapat menurunkan tekanan darah.Rebusan daun salam dianggap lebih aman, efektif dan menimbulkan efek samping lebih sedikit dibandingkan dengan terapi farmakologis (Yunus. 2015). Kandungan 
kalium, minyak atsirih, eugenol dan flavonoid yang yang terdapat pada daun salam efektif dalam menurunan tekanan darah, karena daun salam dapat membantu ginjal mengeluarkan kelebihan cairan dan garam dari dalam tubuh, melancarkan peredaran darah keseluruh tubuh serta memberikan efek rileks pada responden.

Hal ini sesuai pendapat Vania (2012), yang mengatakan bahwa daun salam mengandung zat kimia alami seperti kalium dan alkaloid yang bersifat deuretik yaitu membantu ginjal mengeluarkan kelebihan cairan dan garam dari dalam tubuh, berkurangnya cairan dalam darah akan menurunkan tekanan darah. Sedangkan menurut Junaedi (2013), bahwa kandungan kimia dalam daun salam yang berperan terhadap penurunan tekanan darah adalah flavonoid. Senyawa flavonoid dapat melancarkan peredaran darah keseluruh tubuh dan mencegah terjadinya penyumbatan pada pembuluh darah.Selain itu senyawa flavonoid juga dapat menurunkan Systemic Vascular Resisten (SVR), menyebabkan vasodilatasi dan mempengaruhi kerja ACE inhibitor yang mampu menghambat terjadinya perubahan angiotensin I menjadi angiotensin II. Efek vasodilatasi dan ACE inhibitor dapat menurunkan tekanan darah. Sedangkan menurut Winarto (2008), minyak atsiripada daun salam dapat memberikan efek relaks serta senyawa kimia aromatik, dari kandungan eugenol yang baik untuk mengurangi stress.

Berdasarkan penelitian diatas dapat disimpulkan bahwa penurunan tekanan darah dapat dilakukan dengan menggunakan terapi non farmakologis yaitu dengan daun salam, karena kandungan daun salam mampu menurunkan kadar hormone stress dalam tubuh dan dapat membantu ginjal mengeluarkan kelebihan cairan dan garam dari dalam tubuh, daun salam juga dapat menyebabkan vasodilatasi dan mempengaruhi kerja ACE inhibitor. Karena menyebabkan vasodilatasi dan mempengaruhi kerja ACE inhibitor dapat menghambat perubahan angiotensin I menjadi angiotensin II. Sehingga efek vasodilatasi dan ACE inhibitor tersebut dapat menurunkan tekanan darah, dengan demikian daun salam dapat digunakan sebagai penurunan tekanan darah.

Hasil penelitian ini menunjukkan bahwa tekanan darah sesudah diberikan rebusan daun salam mengalami penurunan dibandingkan sebelum diberikan rebusan daun salam. Hal ini dapat dilihat pada tabel 5 yang menjelaskan bahwa dari 32 responden yang diteliti sebelum diberikan terapi rebusan daun salam penderita yang mengalami hipertensi berat sebanyak 7 responden $(21,9 \%)$ dan setelah diberikan terapi rebusan daun salam sebagian menjadi hipertensi sedang sebanyak 6 responden $(18,8 \%)$, sedangkan sebagian kecil berubah menjadi hipertensi ringan sebanyak 1 responden $(3,1 \%)$, kemudian dari jumlah responden yang mengalami hipertensi sedang sebelum terapi rebusan daun salam sebanyak 9 responden $(28,1 \%)$ dan setelah diberikan terapi rebusan daun salam sebagian menjadi hipertensi ringan sebanyak 8 responden $(25,0 \%)$, sebagian kecil menjadi normal sebanyak 1 responden $(3,1 \%)$. Sedangkan dari 16 responden $(50,0 \%)$ dengan hipertensi ringan sebelum pemberian terapi rebusan daun salam dan setelah diberikan terapi rebusan daun salam seluruhnya responden menjadi kategori normal 
sebanyak 16 responden (50,0\%). Berdasarkan hasil analisis dengan uji statistik Wilcoxon Sign Rank Test dengan menggunakan program SPSS PCfor windows versi 18.0diperoleh nilai $\mathrm{Z}=-5,507$ dimana $\mathrm{Z}>-1,645$ dan $\mathrm{p}=0,000$ dimana $\mathrm{p}<0,05$ maka $\mathrm{H}_{1}$ diterima, artinya terdapat pengaruh pemberian rebusan daun salam terhadap penurunan tekanan darah pada penderita hipertensi di Desa Plosowahyu Kecamatan Lamongan.

Hal ini sejalan dengan penelitian yang dilakukan oleh (Saputra, 2012) yang menujukkan terdapat perbedaan tekanan darah laki-laki dewasa sebelum dan sesudah diberikan rebusan daun salam. Hasil penelitian menunjukkan rata-rata tekanan darah responden sesudah diberikan rebusan daun salam sebesar $105,20 / 71,80 \mathrm{mmHg}$ lebih rendah dari pada sebelum diberikan rebusan daun salam sebesar $118,8 / 77,93 \mathrm{mmHg}$. Hasil analisis yang menunjukkan nilai $\mathrm{p}=0,01$ dimana $\mathrm{p}<0,05$. Hal ini membuktikan bahwa pemberian air rebusan daun salam dirasa cukup efektif untuk membantu menurunkan takanan darah.

Dari hasil penelitian keseluruhan responden setelah mengkonsumsi rebusan daun salam mengalami penurunan tekanan darah yang signifikan. Hal ini dipengaruhi oleh tingkat kepatuhan responden dalam mengonsumsi rebusan daun salam, karena dengan mengonsumsi rebusan daun salam dapat membantu ginjal mengeluarkan kelebihan cairan dan garam dari dalam tubuh, berkurangnya cairan dalam darah dapat menurunkan tekanan darah, karena kecukupan asupan kalium dapat memelihara tekanan darah dan membuat perubahan positif pada tekanan darah pada penderita hipertensi. Minyak atsiri yang menghasilkan aroma khas yang memberikan efek rileks pada responden yang dapat diasumsikan menurunkan tingkat stres yang menjadi faktor pendorong timbulnya hipertensi. Selain itu, senyawa flavonoid pada daun salam juga dapat melindungi pembuluh darah, menjaga kesehatan jantung, melancarkan peredaran darah keseluruh tubuh serta mencegah terjadinya penyumbatan pada pembuluh darah.

Hasil penelitian ini sesuai dengan pendapat (Yunus, 2015), yang mengatakan bahwa daun salam mengandung senyawa flavonoid, yang mana flavonoid mengandung Quarcetin yang berpengaruh sebagai vasodilator, anthipletelet,poliferative yang dapat menurunkan tekanan darah, melindungi pembuluh darah, menjaga kesehatan jantung, perbaikan organ yang sudah rusak akibat dari hipertensi dan mencegah terjadinya infark miokard dan sroke.

Penelitian ini dapat disimpulkan bahwa pemberian air rebusan daun salam dapat menurunkan tekanan darah pada penderita hipertensi, karena kandungan senyawa yang terdapat pada daun salam dapat berpengaruh sebagai vasodilator pembuluh darah dan juga dapat melancarkan peredaran darah keseluruh tubuh sehingga mencegah terjadinya penyumbatan pada pembuluh darah (Manan. Dengan demikiaan diharapkan penderita hipertensi sebaiknya mengonsumsi air rebusan daun salam sebanyak 250cc (1 gelas belimbing) perhari, diminum 2 kali sehari (pagi dan sore) masing-masing setengah gelas $(125 \mathrm{cc})$. Ini bertujuan untuk menurunkan tekanan darah, karena daun salam mampu memberikan manfaat terhadap penderita 
hipertensi, dengan mengonsumsi rebusan daun salam secara rutin dengan dosis pemberian yang sesuai dapat mengontrol tekanan darah pada penderita hipertensi sehingga tekanan darah tetap terjaga dan tidak menimbulkan komplikasi. Efek ini dapat dipertahankan, sehingga dapat membawa manfaat lebih untuk penanganan penyakit hipertensi. Selain mengkonsumsi air rebusan daun salam penderita hipertensi juga harus memperhatikan pola makan, gaya hidup, aktivitas, selalu berolahraga, mengurangi setres, rokok dan banyak garam agar peningkatan tekanan darah dapat dikendalikan.

\section{KESIMPULAN DAN SARAN}

1) Kesimpulan.

a. Sebagian penderita hipertensi mengalami hipertensi ringan sebelum diberikan rebusan daun salam (Syzygium Polyantum).

b. Sebagian besar penderita hipertensi mengalami penurunan tekanan darah menjadi kategori tekanan darah normal setelah diberikan air rebusan daun salam (Syzygium Polyantum).

c. Terdapat pengaruh pemberian rebusan daun salam (Syzygium Polyantum) terhadap penurunan tekanan darah pada penderita hipertensi primer di Desa Plosowahyu Kecamatan Lamongan tahun 2018.

2) Saran

Berdasarkan hasil kesimpulan diharapkan agar penderita hipertensi secara rutin mengonsumsi rebusan daun salam sesuai dengan dosis yang ditentukan tetapi selain mengonsumsi air rebusan daun salam penderita hipertensi juga harus memperhatikan pola makan diimbangi dengan olaraga yang cukup, gaya hidup yang sehat, mengurangi stress, rokok, dan banyak garam serta teratur memeriksakan tekanan darah agar peningkatan tekanan darah dapat dikendalikan.

\section{DAFTAR PUSTAKA}

Dalimartha, S. (2008). Care Your Self Hipertensi. Jakarta: Penebar plus+.

El Manan, M. (2011) .Basmi Keluhan-Keluhan Kesehatan Harian Dengan ObatObat Alami. Yogyakarta: FlashBooks

Hestiantica, Destiara. (2017). Hubungan Pengetahuan dan Riwat hipertensi Dengan Tindakan Pengendalian Tekanan Darah Pada Lansia Di Kelurahan Ampel RW 5 RT 1-5: Surabaya. FKM UNAIR

Junaedi,(2013). Hipertensi Kandas Berkat Herbal. Jakarta: FMedia.

Kowalak, J. P. (2011). Buku Ajar Patofisiologi. Jakarta: EGC. 
Nisa, Intan. (2012). Ajaibnya Terapi Hipertensi Tumpas Penyakit Hipertensi. Jakarta: Dunia Sehat

Prasetyaningrum, Y.I. (2014). Hipertensi Bukan Untuk Ditakuti. Jakarta: Fmedia

Saputra, Vania Aprilia. (2012). Pengaruh Rebusan Daun Salam Terhadap Tekanan Darah Laki-Laki Dewasa. www.repository.maranatha.edu. diakses tanggal 25 Oktober 2017

Waddah, Nurul. (2011). Menaklukan Hipertensi dan Diabetes. Yogyakarta: Multipress

Winarto, W. (2008). Manfaat Bumbu Dapur Untuk Mengatasi Aneka Penyakit. Jakarta: Agro Media Pustaka.

Yunus, dkk. (2015). Identifikasi Senyawa Flavonoid Ekstra Etanol Daun Salam (Syzygium Polyantum) Asal Gorontalo Dengan Menggunakan Kromatografi Lapis tipis Univ. Gorontalo: Diakses dari http://siat.ung.ac.id tanggal 22 Maret 2018. 